\title{
PEMODELAN MATEMATIKA PRODUK NANO SPRAY \\ DAN MAGIC STICK PERUSAHAAN MILLIONAIRE CLUB INDONESIA (MCI) STOCKIST LAMPUNG
}

\author{
Reni Permata Sari ${ }^{1}$, Ummi Rosyidah ${ }^{2}$ \\ ${ }^{1}$ Program Studi Statistika Universitas Nahdlatul Ulama Lampung \\ ${ }^{2}$ Program Studi Pendidikan Matematika Universitas Nahdlatul Ulama Lampung \\ E-mail: renipermatasari71@gmail.com
}

\begin{abstract}
One of the companies engaged in beauty products is Millionaire Club Indonesia (MCI). The products offered are beauty products without chemicals and are certainly safe for women's bodies. The product is called Nano spray and Magic Stick. The MCI company applies a purchase order system in product marketing. So that the MCI company to stock the sales. Consumers can order in advance to get the goods. The purpose of this research is to find out the amount of fluctuation of Nano Spray and Magic Stick sales and to know the minimum purchase order of Nano Spray and Magic Stick in 2019 with mathematical modeling methods and linear programs. The results of the study are as follows: (1) There was a fluctuation (increase or decrease) in sales of Nano Spray and Magic Stick. Nano Spray sales are always more than Magic Stick sales. This proves that Nano Spray enthusiasts are more numerous than Magic Stick enthusiasts. Nano Spray and Magic Stick products, the most sales occurred in the month of 4 (April) and the lowest sales in the month of 12 (December). (2) The form of modeling to minimize Nano Spray and Magic Stick purchase orders in 2019 that is, for is the number of Nano Spray purchase orders in the month-to-month and is the number of Magic Stick purchase orders in the month-to-month. The minimum number of Nano Spray and Magic Stick purchase orders in 2019 is 15,552 units with the number of Nano Spray and Magic Stick purchase orders in 2019 respectively being 8337 units and 7215 units.
\end{abstract}

Keywords: Mathematical Modeling, Nano Spray and Magic Stick Products

\section{PENDAHULUAN}

aat ini permintaan produk Nano Spray dan Magic Stik semakin banyak. Perusahaan MCI menerapkan system purchase order dalam pemasaran produk. Sehingga $\checkmark$ perusahaan MCI melakukan cara stok dalam penjualannya. Konsumen dapat melakukan pemesananan terlebih dahulu untuk mendapatkan barang. Perlunya penyeimbangan antara pemesanan, stok dan penjualan membuat penulis tertarik untuk memodelkan permasalahan tersebut. Untuk membantu perusahaan MCI agar dapat mengembangkan serta mendapatkan keuntungan yang lebih baik lagi. Pemodelan masalah dapat menggunakan program linear. Saat ini program linear telah berkembang menjadi 
salah satu alat standar untuk menyelesaikan masalah-masalah yang timbul dalam suatu perusahaan (Wamiliana, 2015).

Menurut Giordani dan Weir (2002), penyusunan suatu deskripsi dari beberapa perilaku dunia nyata (fenomena-fenomena alam) ke dalam bagian matematika yang atau dunia matematika disebut pemodelan matematika. Model matematis digunakan sebagai rancangan jembatan penghubung masalah nyata yang terjadi dalam kehidupan seharihari (Djati, 2015). Ada dua tipe model matematika, yaitu model bertipe deterministik dan model bertipe empirik. Model deterministik merupakan suatu model matematika yang dibangun dengan berlandaskan hukum-hukum atau sifat-sifat yang berlaku pada sistem. Sedangkan model empirik cenderung kepada fakta yang diberikan oleh sistem atau data. Cara ilmiah untuk mendapatkan data dengan tujuan dan kegunaan tertentu disebut metode penelitian (Sugiono, 2016).

Dalam penguraian bentuk standar pemrograman linear terlebih dahulu akan diketahui model fungsi kendalanya dengan ketidaksamaan dan persamaan seperti $\leq,=$ ,$\geq$. Demikian juga halnya dengan semua variabel, non negatif dan tidak terbatas tandatandanya dan yang harus dapat dibuat dalam bentuk umum untuk memudahkan pembuatan solusinya. Sifat bentuk standar pemrograman linear:

1. Semua fungsi kendala dalam bentuk persamaan dan juga non negatif pada sebelah kanan tanda $(\leq, \geq)$ atau harus lebih besar dari nol.

2. Semua variabelnya non negatif.

3. Semua fungsi objektifnya dapat dinyatakan dengan maksimum atau minimum (Thomas dan Kakiay, 2008).

Beberapa asumsi yang melandasi program linear yaitu:

1. Linearitas berarti bahwa semua fungsi matematis pada model program linear harus merupakan fungsi-fungsi linear.

2. Proporsionalitas berarti bahwa tingkat perubahan atau kecondongan fungsi adalah konstan. Oleh karena itu, perubahan dari ukuran tertentu pada nilai variabel keputusan $\left(\mathrm{x}_{\mathrm{j}}\right)$ akan menghasilkan perubahan yang relatif sama pada nilai fungsi $(\mathrm{Z})$.

3. Aditivitas berarti bahwa untuk setiap fungsi, nilai fungsi total dapat diperoleh dengan menjumlahkan kontribusi-kontribusi individual (untuk fungsi tujuan dan untuk suatu fungsi kendala) dari masing-masing kegiatan.

4. Divisibilitas berarti bahwa unit-unit kegiatan dapat dibagi ke dalam bagian sekecilkecilnya, sehingga nilai-nilai variabel keputusan tidak harus integer (hanya 0 dan 1 atau bilangan bulat) tetapi diperbolehkan non integer (misalnya 875.38; 58.0; 21).

5. Deterministik berarti bahwa semua parameter pada model program linear (yaitu nilai-nilai $\mathrm{C}_{\mathrm{j}}$, $\mathrm{a}_{\mathrm{ij}} \mathrm{dan} \mathrm{b}_{\mathrm{j}}$ ) konstan dan diketahui atau ditentukan secara pasti (Hillier dan Lieberman, 1990).

Tujuan penelitian ini yaitu untuk mengetahui jumlah fluktasi penjualan dan untuk mengetahui purchase order minimum Nano Spray dan Magic Stick tahun 2019 dengan metode pemodelan matematika dan program linear.

\section{METODE PENELITIAN}

Data yang dikumpulkan pada penelitian ini adalah data yang bersumber dari Perusahanaan Millionaire Club Indonesia (MCI) Stockist Nano Spray Lampung. Langkah-langkah pelaksanaan penelitian dan analisis data adalah sebagai berikut: 
1. Mengumpulkan data Permintaan dan Penjualan Produk: Nano Spray dan Magic Stick Tahun 2019.

2. Membuat grafik penjualan Nano Spray dan Magic Stick dan menganalisisnya .

3. Membuat pemodelan matematika.

4. Membuat solusi minimum purchase order Nano Spray dan Magic Stick dan menganalisisnya .

\section{HASIL DAN PEMBAHASAN}

\section{A. Data Penelitian}

Data yang digunakan pada penelitian ini dapat disajikan dalam Tabel 1.

Tabel 1. Jumlah Permintaan dan Penjualan Nano Spray dan Magic Stick Tahun 2019

\begin{tabular}{ccccc}
\hline \multirow{2}{*}{ Bulan } & \multicolumn{2}{c}{ Nano Spray } & \multicolumn{2}{c}{ Magic Stick } \\
\cline { 2 - 5 } & Permintaan & Penjualan & Permintaan & Penjualan \\
\hline 1 & 392 & 435 & 317 & 356 \\
\hline 2 & 596 & 649 & 522 & 551 \\
\hline 3 & 880 & 916 & 734 & 788 \\
\hline 4 & 912 & 958 & 768 & 817 \\
\hline 5 & 845 & 892 & 633 & 664 \\
\hline 6 & 810 & 850 & 680 & 715 \\
\hline 7 & 541 & 574 & 435 & 471 \\
\hline 8 & 625 & 659 & 479 & 519 \\
\hline 9 & 700 & 725 & 561 & 601 \\
\hline 10 & 518 & 557 & 401 & 434 \\
\hline 11 & 351 & 380 & 257 & 291 \\
\hline 12 & 303 & 333 & 213 & 244 \\
\hline
\end{tabular}

Jumlah permintaan dan penjualan Nano Spray dan Magic Stick mengalami penurunan dan peningkatan. Kendala dalam stockist yaitu penyediaan barang yang harus melebihi permintaan dan penjualan sehingga tidak ada konsumen yang dikecewakan akibat barang yang habis.

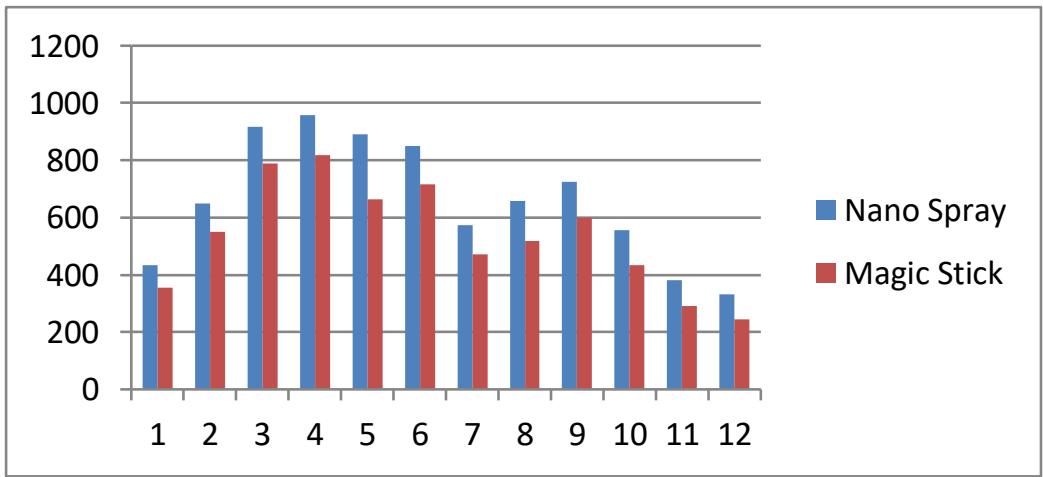

Gambar 1. Grafik Jumlah Penjualan Nano Spray dan Magic Stick Tahun 2019 
Jika barang yang dipesan habis maka barang yang dipesan akan diberikan untuk beberapa waktu yang akan datang, atau sering disebut inden. Oleh karena itu sebuah stockist harus memprediksi berapa barang yang harus dipesan setiap bulannya agar kejadian seperti inden tidak terulang lagi. Hasil penjualan Nano Spray dan Magic Stick dapat dilihat pada Gambar 1.

Grafik menunjukkan penjualan produk Nano Spray terbanyak terjadi pada bulan 4 (April) dan penjualan tersedikit pada bulan 12 (Desember). Untuk penjualan terbanyak pada produk Magic Stick yaitu pada bulan 4 (April) dan penjualan tersedikit pada bulan 12 (Desember). Penjualan produk Nano Spray selalu lebih banyak dari pada penjualan Magic Stick. Terlihat pula setiap bulan penjualan kedua produk tersebut selalu mengalami fluktasi (peningkatan atau penurunan).

\section{B. Pemodelan Matematika}

Pemodelan purchase order Nano Spray dan Magic Stick dengan fungsi objektifnya yaitu meminimumkan purchase order Nano Spray dan Magic Stick dalam satu tahun.

Misal

$X_{i}=$ Banyaknya stok Nano Spray pada bulan ke- $i$

$Y_{i}=$ Banyaknya stok Magic Stick pada Bulan ke- $i$

$W_{i}=$ Banyaknya purchase order Nano Spray pada bulan ke- $i$

$Z_{i}=$ Banyaknya purchase order Magic Stick pada bulan ke- $i$

Fungsi Objektivitas

$\operatorname{Min} \sum_{i=1}^{12}\left(W_{i}+Z_{i}\right)$

Kendala stok minimum akhir bulan( minimal 30 unit)

$X_{i+1}-X_{i} \geq 30 ; i=1,2, \ldots, 11$

$Y_{i+1}-Y_{i} \geq 30 ; i=1,2, \ldots, 11$

Kendala Permintaan Nano Spray

$X_{1} \geq 392$

$X_{2} \geq 596$

$X_{3} \geq 880$

$X_{4} \geq 912$

$X_{5} \geq 845$

$X_{6} \geq 810$

$X_{7} \geq 541$

$X_{8} \geq 625$

$X_{9} \geq 700$

$X_{10} \geq 518$

$X_{11} \geq 351$

$X_{12} \geq 303$

Kendala Permintaan Magic Stick

$Y_{1} \geq 317$

$Y_{2} \geq 522$

$Y_{3} \geq 734$

$Y_{4} \geq 768$ 
$Y_{5} \geq 633$

$Y_{6} \geq 680$

$Y_{7} \geq 435$

$Y_{8} \geq 479$

$Y_{9} \geq 561$

$Y_{10} \geq 401$

$Y_{11} \geq 257$

$$
Y_{12} \geq 213
$$

Kendala stock Nano Spray bulan ke- $i$

$X_{1} \leq W_{1}$

$X_{2} \leq W_{2}+\left(W_{1}-435\right)$ atau $X_{2}+435 \leq W_{1}+W_{2}$

$X_{3} \leq W_{3}+\left[W_{2}+\left(W_{1}-435\right)-649\right]$ atau $X_{3}+1084 \leq W_{1}+W_{2}+W_{3}$

Dengan cara yang sama diperoleh:

$$
\begin{aligned}
& X_{4}+2000 \leq W_{1}+W_{2}+W_{3}+W_{4} \\
& X_{5}+2958 \leq W_{1}+W_{2}+W_{3}+W_{4}+W_{5} \\
& X_{6}+3850 \leq W_{1}+W_{2}+W_{3}+W_{4}+W_{5}+W_{6} \\
& X_{7}+4700 \leq W_{1}+W_{2}+W_{3}+W_{4}+W_{5}+W_{6}+W_{7} \\
& X_{8}+5274 \leq W_{1}+W_{2}+W_{3}+W_{4}+W_{5}+W_{6}+W_{7}+W_{8} \\
& X_{9}+5933 \leq W_{1}+W_{2}+W_{3}+W_{4}+W_{5}+W_{6}+W_{7}+W_{8}+W_{9} \\
& X_{10}+6658 \leq W_{1}+W_{2}+W_{3}+W_{4}+W_{5}+W_{6}+W_{7}+W_{8}+W_{9}+W_{10} \\
& X_{11}+7215 \leq W_{1}+W_{2}+W_{3}+W_{4}+W_{5}+W_{6}+W_{7}+W_{8}+W_{9}+W_{10}+W_{11} \\
& X_{12}+7595 \leq W_{1}+W_{2}+W_{3}+W_{4}+W_{5}+W_{6}+W_{7}+W_{8}+W_{9}+W_{10}+W_{11}+ \\
& W_{12}
\end{aligned}
$$

Kendala stock Magic Stick bulan ke- $i$.

$$
\begin{aligned}
& Y_{1} \leq Z_{1} \\
& Y_{2} \leq Z_{2}+\left(Z_{1}-356\right) \text { atau } Y_{2}+356 \leq Z_{1}+Z_{2} \\
& Y_{3} \leq Z_{3}+\left[Z_{2}+\left(Z_{1}-356\right)-551\right] \text { atau } Y_{3}+907 \leq Z_{1}+Z_{2}+Z_{3}
\end{aligned}
$$

Dengan cara yang sama diperoleh:

$$
\begin{aligned}
& Y_{4}+1695 \leq Z_{1}+Z_{2}+Z_{3}+Z_{4} \\
& Y_{5}+2512 \leq Z_{1}+Z_{2}+Z_{3}+Z_{4}+Z_{5} \\
& Y_{6}+3176 \leq Z_{1}+Z_{2}+Z_{3}+Z_{4}+Z_{5}+Z_{6} \\
& Y_{7}+3891 \leq Z_{1}+Z_{2}+Z_{3}+Z_{4}+Z_{5}+Z_{6}+Z_{7} \\
& Y_{8}+4362 \leq Z_{1}+Z_{2}+Z_{3}+Z_{4}+Z_{5}+Z_{6}+Z_{7}+Z_{8} \\
& Y_{9}+4881 \leq Z_{1}+Z_{2}+Z_{3}+Z_{4}+Z_{5}+Z_{6}+Z_{7}+Z_{8}+Z_{9} \\
& Y_{10}+5482 \leq Z_{1}+Z_{2}+Z_{3}+Z_{4}+Z_{5}+Z_{6}+Z_{7}+Z_{8}+Z_{9}+Z_{10} \\
& Y_{11}+5916 \leq Z_{1}+Z_{2}+Z_{3}+Z_{4}+Z_{5}+Z_{6}+Z_{7}+Z_{8}+Z_{9}+Z_{10}+Z_{11} \\
& Y_{12}+6207 \leq Z_{1}+Z_{2}+Z_{3}+Z_{4}+Z_{5}+Z_{6}+Z_{7}+Z_{8}+Z_{9}+Z_{10}+Z_{11}+Z_{12}
\end{aligned}
$$

Kendala maksimum purchase order Nano Spray:

$W_{i} \leq 1000 \quad ; \quad i=1,2, \ldots, 12$

Kendala maksimum purchase order Magic Stick:

$Z_{i} \leq 850 \quad ; i=1,2, \ldots, 12$ 
Kendala hubungan Nano Spray dan Magic Stick

$$
Z_{i} \leq W_{i} \quad ; i=1,2, \ldots, 12
$$

\section{Solusi Minimum Purchase Order Nano Spray dan Magic Stick}

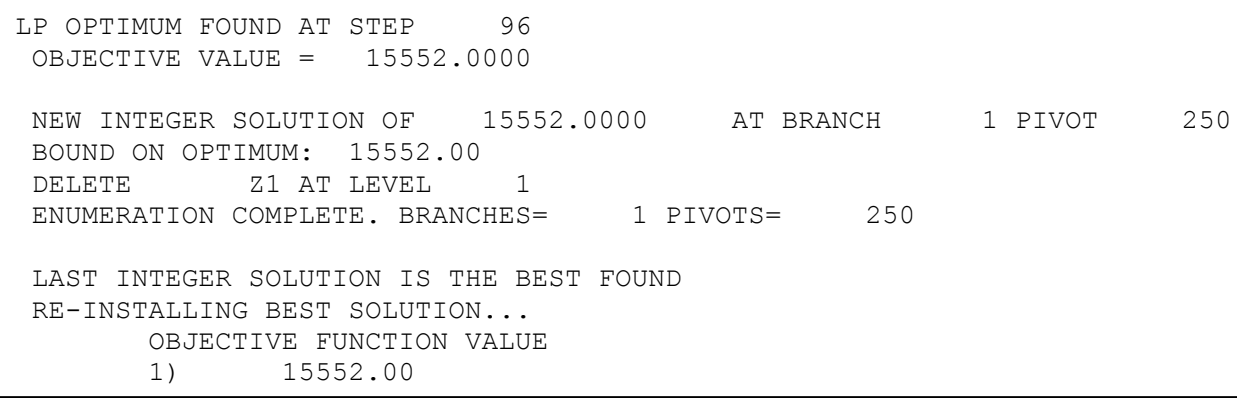

Gambar 2. Hasil solusi minimum purchase order Nano Spray dan Magic Stick

Solusi dari Purchase Order Minimum Nano Spray dan Magic Stick dapat disajikan dalam Tabel 2.

Tabel 2. Solusi dari Purchase Order Minimum Nano Spray dan Magic Stick

\begin{tabular}{|c|c|c|}
\hline $\mathrm{NO}$ & VARIABLE & VALUE \\
\hline 1 & W1 & 596 \\
\hline 2 & W2 & 465 \\
\hline 3 & W3 & 1000 \\
\hline 4 & W4 & 1000 \\
\hline 5 & W5 & 850 \\
\hline 6 & W6 & 1000 \\
\hline 7 & W7 & 791 \\
\hline 8 & W8 & 604 \\
\hline 9 & W9 & 689 \\
\hline 10 & W10 & 755 \\
\hline 11 & W11 & 587 \\
\hline 12 & W12 & 0 \\
\hline 13 & $\mathrm{Z1}$ & 596 \\
\hline 14 & $\mathrm{Z} 2$ & 464 \\
\hline 15 & $\mathrm{Z} 3$ & 850 \\
\hline 16 & $\mathrm{Z4}$ & 553 \\
\hline 17 & $\mathrm{Z} 5$ & 850 \\
\hline 18 & Z6 & 691 \\
\hline
\end{tabular}




\begin{tabular}{ccc}
\hline 19 & Z7 & 745 \\
\hline 20 & Z8 & 604 \\
\hline 21 & Z9 & 520 \\
\hline 22 & Z10 & 755 \\
\hline 23 & Z11 & 587 \\
\hline 24 & Z12 & 0 \\
\hline
\end{tabular}

Jika menginginkan purchase order Nano Spray dan Magic Stick menjadi minimum dalam setahun maka, purchase order Nano Spray dan Magic Stick pada bulan Januari adalah 596 unit dan 596 unit. Untuk purchase order Nano Spray dan Magic Stick pada bulan Februari yaitu 465 unit dan 464 unit. Purchase order Nano Spray dan Magic Stick pada bulan Maret yaitu 1000 unit dan 850 unit. Purchase order Nano Spray dan Magic Stick pada bulan April yaitu 1000 unit dan 553 unit. Purchase order Nano Spray dan Magic Stick pada bulan Mei yaitu 850 unit dan 850 unit. Purchase order Nano Spray dan Magic Stick pada bulan Juni yaitu 1000 unit dan 691 unit. Purchase order Nano Spray dan Magic Stick pada bulan Juli yaitu 791 unit dan 745 unit. Purchase order Nano Spray dan Magic Stick pada bulan Agustus yaitu 604 unit dan 604 unit. Purchase order Nano Spray dan Magic Stick pada bulan September yaitu 689 unit dan 520 unit. Purchase order Nano Spray dan Magic Stick pada bulan Oktober yaitu 755 unit dan 755 unit. Purchase order Nano Spray dan Magic Stick pada bulan November yaitu 587 unit dan 587 unit. Purchase order Nano Spray dan Magic Stick pada bulan Desember sama dengan nol. Purchase order pada bulan Desember sama dengan nol akibatnya stok pada tahun berikutnya di bulan Januari tidak ada. Jadi jumlah purchase order Nano Spray dan Magic Stick pada tahun 2019 yaitu 8337 unit dan 7215 unit.

\section{KESIMPULAN}

Berdasarkan dari hasil analisis yang dilakukan, maka dapat disimpulkan bahwa:

1. Terjadi fluktasi (peningkatan atau penurunan) pada penjualan Nano Spray dan Magic Stick. Untuk Penjualan Nano Spray selalu lebih banyak dari pada penjualan Magic Stick. Hal ini membuktikan bahwa peminat Nano Spray lebih banyak dibandingkan peminat Magic Stick. Produk Nano Spray dan Magic Stick, penjualan terbanyak terjadi pada bulan 4 (April) dan penjualan tersedikit pada bulan 12 (Desember).

2. Bentuk pemodelan untuk meminimalkan purchase order Nano Spray dan Magic Stick pada tahun 2019 yaitu $\sum_{i=1}^{12} W_{i}+Z_{i}$, untuk $W_{i}$ adalah banyaknya purchase order Nano Spray pada bulan ke- $i$ dan $Z_{i}$ adalah banyaknya purchase order Magic Stick pada bulan ke- $i$. Jumlah minimal purchase order Nano Spray dan Magic Stick pada tahun 2019 yaitu 15.552 unit dengan jumlah masing-masing purchase order Nano Spray dan Magic Stick pada tahun 2019 berturut-turut adalah 8337 unit dan 7215 unit. 


\section{DAFTAR PUSTAKA}

Dym, C.L \& Ivey, E.S. (1980). Principles of Mathemathical Modelling. New York: Academic Press.

Giordani, F.R. \& Weir, M.D. (2002). Differential Equations A Modelling Approach.New York: AddisonWesley Publishing Company.

Hillier, F.S. \& Lieberman, G.J. (1990). Pengantar Riset Operasi, Jilid 1, Edisi Kelima. Jakarta: Erlangga. Kerami, Djati. (2015). Pemodelan Matematis. Tangerang Selatan: Universitas Terbuka.

Lind, Douglas. (2009). Teknik-teknik Statistika dalam Bisnis dan Ekonomi. Jakarta: Salemba Empat.

Subagyo, et al. (1985). Dasar-Dasar Operations Research, Edisi Kedua. Yogyakarta: BPFE.

Sugiono, S. (2016). Metode Penelitian Kuantitatif, Kualitattif, dan R\&G. Bandung: Alfabeta.

Thomas, J \& Kakiay. (2008). Pemograman Linier Metode dan Problema. Yogyakarta: Andi Yogyakarta.

Wamiliana. (2015). Program Linear Teori dan Terapannya. Bandar Lampung. CV.Anugrah Utama Raharja (AURA).

Yanto. (2016). Statistika Inferensia untuk Penelitian dengan Minitab. Yogyakarta: ANDI. 